\title{
«Прямая речь»: из выступлений участников круглого стола \\ «Реформирование российской тепло- и электроэнергетики: итоги, текущие проблемы и вызовы»
}

Д.С. Кудряшов, дочент кафедры электроснабжения горных и промышленных предприятий КузГТУ (Кемерово):

- Если бы существующая система регулирования была идеальной и всех устраивала, не было бы необходимости переходить на модель «альткотельной». Та ситуация, которая была в Рубцовске - с текущими крышами, ржавеющим оборудованием ТЭЦ, холодом в домах, сегодня наблюдается во многих небольших городах страны. Они буквально находятся на грани выживания. Даже некоторые крупные станции начали разваливаться. Тарифы на тепло для населения настолько низкие, что собственники потеряли интерес развивать станции. Как только с ТЭЦ уходят промышленные потребители, которые тянули на себе «перекрестку» (банкротятся, строят свои котельные), вся ее экономика рушится. В одном из больших городов администрация города планирует построить 21 газовую котельную, потому что владельцу крупной местной ТЭЦ при существующем уровне тарифа было невыгодно строить новые котлы и тянуть теплотрассу в развивающиеся районы. Такая система ценообразования порочна насквозь.

Нам сегодня рассказали о работающем варианте защиты инвестиций, который Минэнерго и Сибирская генерирующая компания реализовали в Алтайском крае. Понятно, существуют механизмы концессии, ГЧП, которые тоже создают стимулы для инвесторов, но они по-другому работают. Альтернативы альткотельной пока я не вижу. И, конечно, в каждом городе обязательно должна быть разработана схема теплоснабжения. Может быть, стоит даже обязать муниципалитеты разработать такие схемы ввести государственные требования, может, штрафные санкции какие-то... как при невыполнении ДПМ?

И хотелось бы поддержать Е.А. Косогову (см. статью в этом номере) по защите организаций теплоснабжения от контролеров. Как только инвестор заходит на объект, тут же появляются восемь 
контролирующих органов, которые выставляют многомиллионные штрафы - буквально в первые четыре-шесть месяцев. Экологи, Роспотребнадзор, Ростехнадзор, Росгвардия... Требования по безопасности к котельной, которая снабжает полторы тысячи человек, сегодня, как в зоне: заборы, технические средства, охрана с оружием. Но только на зоне это нужно, чтобы оттуда не сбежали, а тут - чтобы не проникли. Обеспечение таких технических мероприятий на одну котельную тянет более чем на пять миллионов рублей. Это какой-то беспредел. Кто при таких условиях пойдет в отрасль?

А ведь в любой момент тариф могут урезать. В Кузбассе был такой случай в одном из шахтерских городов: население платило за тепло около 1800 руб. Поскольку шахта нормально работала, доходы позволяли. Но в какой-то момент по какой-то причине собственник не сумел вовремя документы оформить. РЭК снизил тариф на 22\%. В итоге предприятие обанкротилось...

К сожалению, в отрасли стало чуть ли не нормой, когда предприятия теплоснабжения банкротятся через 2-3 года. Пока не зайдет большая компания, которая сможет и захочет все содержать - называйте ее хоть камикадзе, самоубийцей, хоть благотворителем - коммунальное хозяйство ходит по грани... Это неблагодарный бизнес. Мало того, что бесконечно приходится уговаривать жителей поставить приборы учета, еще и с управляющими компаниями приходится разбираться. Они иногда горячую воду сливают прямо в канализацию, потому что не хотят заниматься внутридомовыми сетями, гидравликой. Без приборов учета они за эти потери никакой ответственности не несут.

И главное - это же все не вчера появилось. Десятилетиями в коммунальную энергетику никто не вкладывал, тарифы занижались, но бесконечно так продолжаться не может. А сейчас, когда появилась возможность что-то исправить, жители жалуются, что цены растут... Но это на самом деле вопрос не прибыли, а иногда даже - не развития, а элементарного выживания.

В.А. Жихарев, начальник Департамента развития розничного рынка и сетей Ассочичаџии (НП) «Сообщество потребителей энергии»:

- Мне совершенно непонятны рассуждения энергетиков о том, что они несут огромные издержки по содержанию и развитию генерирующих мощностей. На самом деле все это оплачивается 
потребителями. Даже заемные средства могут быть получены только при наличии платежеспособного спроса. При этом тарифная нагрузка на них, несмотря на все ограничения и все регулирование, растет гораздо быстрее инфляции.

В 2006-м и 2019 г. я делал расчеты по структуре себестоимости продукции для одного из ведущих новосибирских предприятий. За этот период среднемесячная стоимость электроэнергии для него (в наиболее дорогие месяцы) выросла с 24,5 млн руб. до 95 млн руб. (до 36,2 млн руб. в ценах 2006 г.). По сути, стоимость 1 кВт·ч для этого предприятия в полтора раза обогнала инфляцию!

На рисунке представлена информация о средних ценах электроэнергии для промышленных потребителей Соединенных Штатов Америки, Европы и некоторых регионов России. Как видим, среднее промышленное предприятие в США и Европе платит за электроэнергию существенно меньше, чем в Новосибирске, и значительно меньше, чем в шести регионах Российской Федерации. Все это говорит о том, что наши предприятия с точки зрения конкурентоспособности сильно уступают зарубежным. То преимущество в дешевых энергоресурсах, которое у них имелось некоторое время назад, сегодня исчезло. И теперь, когда изучаешь счета-фактуры за поставки электроэнергии, убеждаешься, что в последнее время ее стоимость растет в 4-5 раз быстрее, чем инфляция.
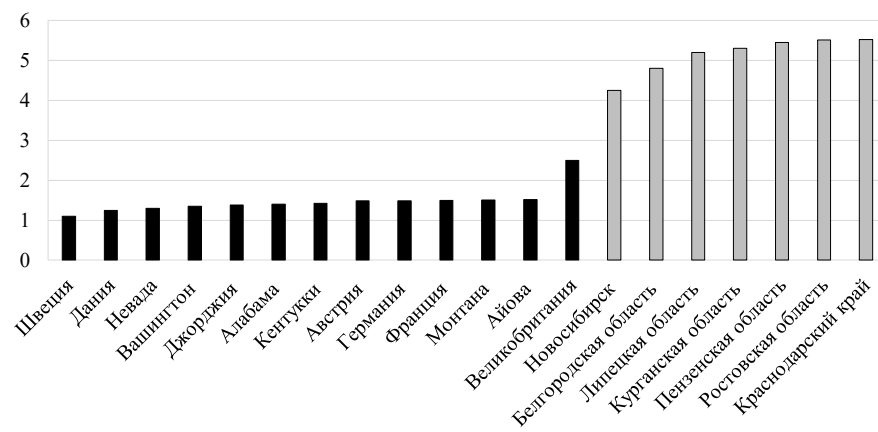

Сравнение цен электроэнергии в России с промышленно развитыми штатами США и странами Европы по индексу ППС, руб./кВт·ч 
Хотел бы также отметить, что современное состояние энергетики таково, что многие предприятия - не только крупные, но даже малые, могут обеспечивать свои потребности в энергии собственными силами. Мы рассчитали динамику роста цен на электроэнергию для промышленных потребителей от трех различных источников с 2009 г. по 2019-й и экстраполировали до 2028 г. По расчетам, отмечается очень существенное (с 2 до 8 руб./кВт·ч к 2028 г.) опережение стоимости электроэнергии, отпускаемой промышленным потребителям с учетом затрат на передачу; чуть медленнее (с 1,3 до 4 руб./кВт·ч) дорожает энергия без учета затрат на передачу и практически не растет (1,5-1,7 руб.) стоимость электроэнергии при ее генерировании на собственном источнике из побочных продуктов основного производства (в нашем случае газ). Приведенные факты говорят о том, что потребители имеют весьма серьезные стимулы и определенные возможности для самообеспечения и экономии на электроэнергии.

Важный вывод, которой должны отсюда сделать энергетики: их роль ослабевает. Это не значит, что централизованная система энергоснабжения должна быть разрушена, но взаимоотношения перестраиваются таким образом, что крупные тепловые и электрические станции перестают быть центральными участниками процесса энергообеспечения.

Обозначу наиболее важные перспективные тенденции развития отрасли:

• к 2022 г. у крупных промышленных потребителей электроэнергии будет в собственности более 22 ГВт генерации с коэффициентом использования установленной мощности в среднем выше, чем у оптовой генерации;

- в 54 субъектах Российской Федерации уже сегодня потребители электроэнергии на уровне напряжения ВН (110 кВ и выше), CH1 (35 кB) могут строить генерацию с резервными агрегатами с окупаемостью 10 лет;

- International Energy Agency оценивает мировой потенциал управления спросом к 2040 г. в размере 187 ГВт (соответствует установленной мощности Австралии и Италии вместе взятых), в 1 млрд потребителей и 11 млрд присоединённых устройств, что позволит сэкономить 270 млрд долл. инвестиций в энергетическую инфраструктуру; 
- в 2016 г. в США по всем территориям, отнесённым к RTO/ ISO, в программах управления спросом участвовало более 9 млн потребителей суммарной мощностью 28673 МВт, что составляет $5,7 \%$ от спроса;

- в Массачусетсе (Rhode Island) National Grid в сотрудничестве с провайдерами DR CPower, EnerNOC, and IPKeys в рамках программы управления спросом платят потребителям за участие в программе 20 долл./кВт и 0,75 долл./кВт•ч - снижения потребления.

Однако в России ни в документах планирования, ни в текущем развитии электроэнергетики эти реалии не учитываются. Новый инвестиционный цикл (ДПМ- 2) фактически нацелен на старые технологии (продление ресурса ПСУ) и «цифровизацию» функций сетевой монополии. Наращиваются объёмы неконкурентных отношений, надбавок и субсидий (перекрёстное субсидирование, «вынужденная» генерация, ДПМ, особые условия конкурентного отбора мощности для новых генерирующих объектов, субсидирование Северного Кавказа, Дальневосточного федерального округа, Крыма, Калининграда, Бурятии и др., резервируемая максимальная мощность, льготное технологическое присоединение до 150 кВт и пр.). В целом, по нашему мнению, формируется дорогостоящая и неповоротливая энергосистема, гарантирующая доходы и отсутствие рисков для энергокомпаний и ориентированная на консервацию модели «рынка продавца». 